\title{
The Application Research of Building Information Model in the Project Cost Control
}

\author{
CHEN Zhuo ${ }^{1, \text { a }}$ \\ ${ }^{1}$ Hubei Polytechnic Institute, Xiaogan 432000, China \\ achenzhuo1212@126.com
}

Keywords: Building Information Model; Project Cost Control; Whole Process

\begin{abstract}
The whole process of cost control in project construction are popular, but for various reasons in the actual implementation of how to become a mere formality. With the development of information technology, building information model and entered the practical stage in domestic has obtained the good effect on multiple projects, get the industry wide attention. In order to promote the whole process of cost control, should introduce the building information model in project construction management. Analysis of building information model in different role of the various stages of the whole process of cost control, the application of different forms of building information model and its difficulties, the whole process of construction project cost control of building information model application, implementation has reference value for the promotion of the whole process of cost control.
\end{abstract}

\section{Introduction}

Whole process cost control in project decision-making stage, design stage, project tendering and bidding, construction stage and completion settlement stage of the construction project cost incurred amount control within the approved limits, and correct the deviation at any time, to ensure that the division, disciplines to achieve the goals of their investment, to get the best economic and social benefits. But in the construction units, design units and construction units due to management style and technology level backward information such as the actual conditions of miscommunication, the whole process of cost control is difficult to realize. Analysis of the implementation difficulties lies in process is not perfect and the data information [1-2]. Process is not standard cause human control factors increase, the similarity between the various projects are too low, the applicability of the whole process of cost control is not strong; Imperfect information in the whole process of cost control of systemic demands were not met, the construction process to separate, reach the whole process cost control target.

Building information model is based on the three-dimensional digital technology, integrated information all kinds of construction engineering projects of engineering data model [3]. The technology for construction units, design units and construction units such as the staff to build a visual digital architectural model, for the project decision-making, design, bidding, construction and completion to provide a collaborative management platform, make the whole construction project in all stages to realize effective management. Building information model is fully digital, in its use in different stages of the process, can be modified at any time to add the model of all kinds of engineering information, in order to meet the diverse needs of the project management. The characteristics of the building information model the dynamic change can meet the requirements of the whole process of cost control, to provide the whole process of construction project cost control key technical support.

\section{Building information model related research}

BIM (building information modeling), the concept of building information model is the first in more than 30 years ago, Professor Charles M. Eastman by computer aided design. Building information model integrated the geometric model of all information, functional requirements and 
component performance, will be a construction project throughout the life cycle of all information into a separate building model, but also include the construction schedule, construction, maintenance and management of the process of information [4]. BIM technology is at the heart of links with information engineering, the information like blood, into every corner of the project. From planning to design, from construction to the property, if enough accurate information can be real-time transmission to the stages of the project, the major professional can also take this synergy in hand, together to create a "information with design, coordination and create a parallel" in the new era. Based on BIM in whole life period management framework, the framework including data layer, model layer, and network layer and application framework, as shown in figure 1.

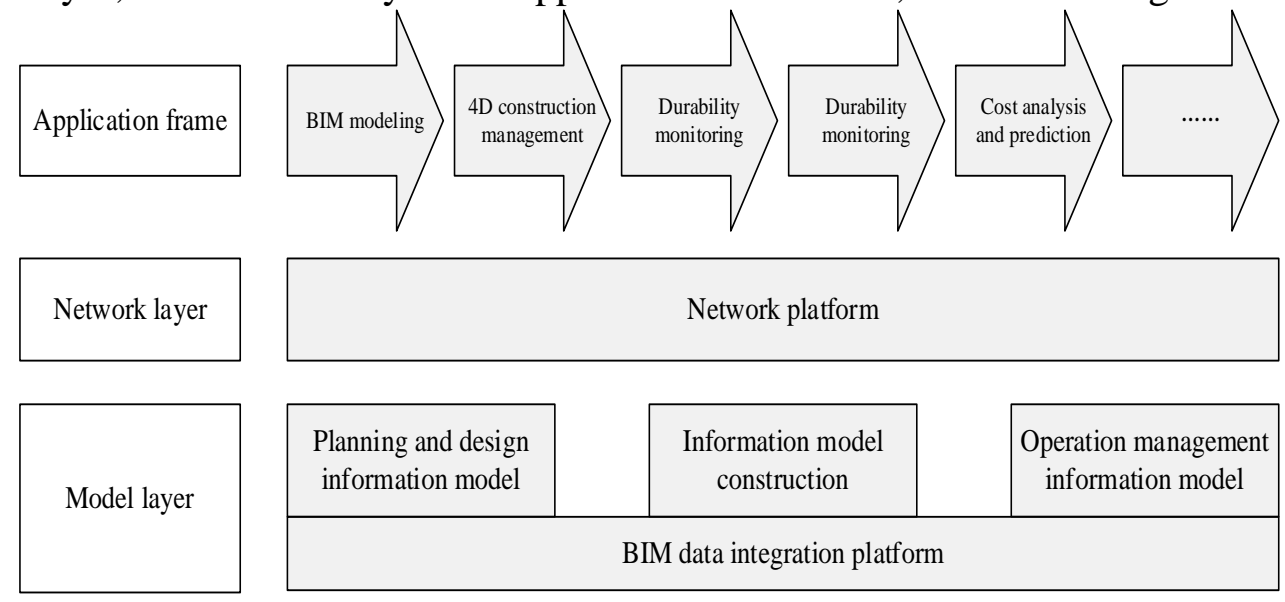

Figure 1. Framework of BIM in whole life period management

$\mathrm{BIM}$ is a 3D technology based information management software, through its function, the development and application in the field of analysis can be concluded that both at home and abroad, the development of whole life cycle of BIM is the best and effective means of municipal engineering construction management, it can bring is operational and efficient information development model and the improvement of municipal engineering construction many targeted Suggestions. Therefore, we should vigorously promote the application of building information model in project cost control [5].

\section{The whole process of project cost control model}

In this paper, based on the life cycle of the project and the project life cycle is contained in the basic content of establishing a project entire process cost control model, as shown in figure 2 . This model will be the entire life cycle of project activities and processes the hierarchical decomposition of the hierarchical decomposition according to the principle of activity-based management, first will be an engineering project as a whole process of project activities, and then expand the activities of the project in accordance with the two dimensional method to decompose step by step, on the one hand, through the process analysis to identify constitute a process of all activities; On the other hand to activity analysis to determine the effectiveness of these activities. Then based on hierarchical analysis, analysis to determine the activity and the process of constructing a process model of a specific project, and with it as the base and starting point of the whole process of cost control.

The picture is a related project activities and process of hierarchical model, drawing in practical work must according to the actual situation of the specific engineering project, in accordance with the relevant activity based management activities. A whole process of the project activity is a process by a series of points, points, and the child process until the project specific activity and specific activity process. 


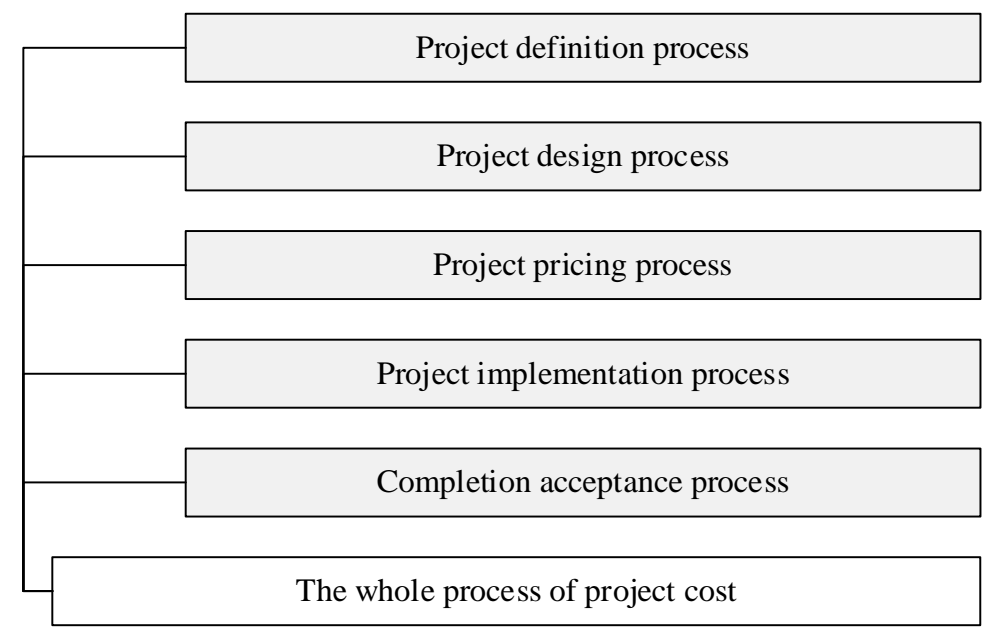

Figure 2. The function module of whole process of project cost control model

\section{The whole process engineering cost control method based on building information model}

The whole process of cost control can be used for the whole process of the project, the various processes or sub-processes, and even various specific activities in the process of cost control. By this method the cost control method based on process model and a series of specific control methods. This method with the traditional biggest difference is that the project cost control method of control object, control link and control way is different. The traditional cost control method mainly from settlement link of project cost control, not geared to the needs of the whole process of cost control, traditional cost management method in the aspect of cost control is very prominent. In this paper, based on the whole process of project cost control, building information model is in order to overcome these defects in the traditional cost management method. Based on building information model of the whole process of project cost control concrete steps as shown in figure 3.

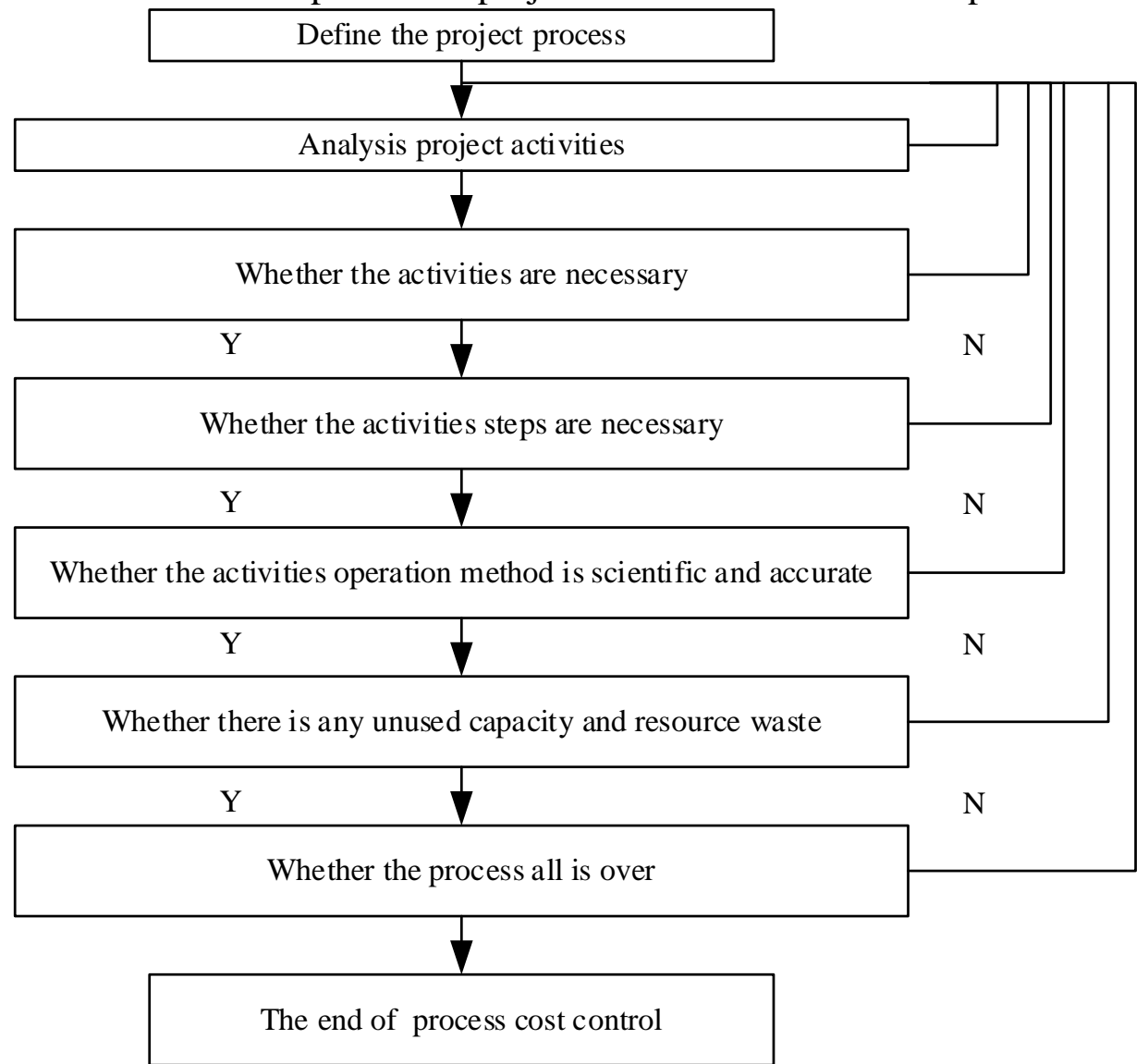

Figure 3. The whole process engineering cost control method based on building information model 
It can be seen from the model, the cost control method based on process is a cycle of dynamic cost control method, this method is that at the completion of the whole process of a project or process, the son of some specific activities, will make the whole process is not yet complete part of the activities of the specific activities, such as environmental activities and activities have occurred some changes, so must review and analysis of the necessity, the activities of science and a series of problems. The key content of project cost control is one of the two loops, namely the whole process control and continuous improvement cycle, and each concrete activities of process control and continuous improvement cycle. The two loops is the core of cost control method based on the process.

\section{Conclusion}

Building information model is the latest achievements in information technology application in the field of construction, in order to make the building information model can really play a role in the construction field in China, better for the whole process of cost control, cost of personnel must do the following: first, the government should establish the national standards system of building information model, for the engineering data sharing of the information; Second, the government should be to improve the domestic construction management mode, the relationship between construction parties, eliminate the artificial barriers of building information model application; In the end, the government, companies and software vendors should be coordinated to the application of building information model, make the building information model can catch on construction field in China as soon as possible, in order to give full play to its positive role in the whole process of cost control.

\section{Acknowledgements}

Foundation project: The standard research on students' professional ability in the major of higher vocational engineering cost, Hubei Provincial Education Science Subject During The 12th Five-Year Plan Period Of China (No. 2012B320), 2012. Host: Zhuo Chen.

\section{References}

[1] Succar B: Automation in Construction, 2009, 18(3): 357-375.

[2] Azhar S: Leadership and Management in Engineering, 2011, 11(3): 241-252.

[3] Hartmann T, Fischer M, Haymaker J: Advanced Engineering Informatics, 2009, 23(1): 57-67.

[4] Sacks R, Koskela L, Dave B A: Journal of construction engineering and management, 2010, 136(9): 968-980.

[5] Gopal A, Gosain S: Information Systems Research, 2010, 21(4): 960-982. 